\title{
Implementasi Routing Protocol Babel pada Mobile Ad Hoc Network (MANET)
}

\author{
Aditya Wijayanto ${ }^{\# 1}$, Rifki Adhitama*2 \\ \# Fakultas Teknologi Industri dan Informatika, Institut Teknologi Telkom Purwokerto \\ Jl. D.I Panjaitan 128 Purwokerto, Jawa Tengah, Indonesia \\ 1 aditya.wijayanto@ittelkom-pwt.ac.id \\ ${ }^{2}$ rifki@ittelkom-pwt.ac.id
}

Accepted on September 28, 2018

\begin{abstract}
Abstrak
Perangkat penghubung data nirkabel diperlukan agar parangkat bergerak (mobile device) dapat berkomunikasi satu dengan yang lain. Manet merupakan sebuah model jaringan tanpa kabel (wireless) dari perangkat mobile yang bergerak secara dinamis dan kapan saja tanpa menggunakan infrastruktur yang tetap. Pada beberapa kondisi seperti pemulihan daerah bencana dan medan perang dimana infrastruktur komunikasi data rusak atau tidak dapat dimanfaatkan, teknologi mobile ad-hoc network dapat digunakan untuk komunikasi data alternative. Untuk memaksimalkan dalam pemanfaatan dan penggunaan system jaringan MANET terutama pada bagian penentuan dan pemilihan rute terbaik untuk node dapat terhubung, dari node sumber ke node tujuan agar lebih optimal. Penelitian ini dilakukan untuk membuktikan routing protocol Babel dapat diterapkan pada Mobile Ad-Hoc Network dengan pengujian secara langsung menggunakan node Single Board Computer. Pengujian dilakukan dengan jumlah node sebanyak 4 node, serta lokasi pengujian pada Lapangan Graha Sabha Permana. Hasil pengujian menunjukkan semua node dapat terhubung dengan baik dan ketika terdapat node yang rusak,node dapat memilih rute terbaik sehingga proses komunikasi pada MANET dapat berlangsung dengan stabil.
\end{abstract}

Keywords: manet, routing protocol, babel, networking

\section{PENDAHULUAN}

$\mathbf{P}$ erangkat penghubung data nirkabel diperlukan agar perangkat bergerak nirkabel (wireless mobile device) dapat berkomunikasi satu dengan yang lain. Pada beberapa kondisi seperti pada pemilihan daerah bencana dan medan perang dimana infrastruktur komunikasi data rusak atau tidak dapat dimanfaatkan[1]. MANET sekumpulan simpul bergerak nirkabel yang dapat berinteraksi dan berkomunikasi satu sama lain tanpa memiliki struktur yang terpusat dan terbangun[2]. MANET dapat dibentuk oleh beberapa mobile node tanpa adanya pusat administrasi dan infrasturktur khusus sehingga mobile host yang terhubung dengan wireless dapat bergerak bebas dan atau juga berperan sebagai router[3]. Kemudahan dan kepraktisan dalam penggunaannya membuat system jaringan MANET terus dikembangkan oleh para peneliti, terutama bidang jaringan computer. Untuk memaksimalkan dalam pemanfaatan dan penggunaan system jaringan MANET maka perlu untuk dikembangkan system jaringan ini, terutama pada bagian penentuan dan pemilihan rute terbaik untuk node dapat terhubung. Agar pemanfaatannya optimal,

MANET membutuhkan algoritma routing yang handal sehingga paket - paket data yang dikirmkan simpul sumber dapat diterima dengan utuh oleh simpul tujuan. Adaptasi terhadap kondisi jaringan yang tidak terlalu tetap ini bisa ditangani oleh metode routing reaktif, proaktif atau hybrid. Babel termasuk dalam routing 
protocol proaktif. Babel adalah salah satu protokol routing distance vector yang memiliki performa fast convergence dan fast route repair time [4]. Namun disamping kecepatan konvergensi yang dimilikinya, Babel memiliki frekuensi perubahan rute yang paling besar daripada routing BATMAN dan OLSR [5]. Babel didesain untuk melakukan pemilihan rute secara fleksibel. Babel menggunakan sebuah feasibility condition yang menjamin tidak adanya routing loop, router akan mengabaikan pembaharuan rute yang tidak memenuhi feasibility condition [6]. Babel dapat juga disebut routing protocol hybrid, dalam arti bahwa dapat membawa rute untuk beberapa protokol lapisan jaringan (IPv4 dan IPv6) [4]. Penelitian ini dilakukan untuk membuktikan routing protocol Babel dapat diterapkan pada Mobile Ad-Hoc Network dengan pengujian secara langsung menggunakan node Single Board Computer.

\section{TINJAUAN PUSTAKA}

Mobile ad-hoc network terbentuk dari sekian banyak host yang terkoneksi melewati router tanpa infrastruktur yang tetap dan sering berubah - ubah. Pada dasarnya MANET adalah sekumpulan simpul bergerak nirkabel yang dapat berinteraksi dan berkomunikasi satu sama lain tanpa memiliki struktur yang terpusat dan terbangun [7].

Melakukan pengukuran performansi dari MANET yang telah diimplementasikan QoS dalam melayani paket data multimedia yang berjalan di atas UDP. Ada beberapa teknik yang sering digunakan dalam implementasi QoS, yang diterapkan pada topik ini adalah Differentiated Service. Teknik ini menandai paket yang akan melewati jaringan dengan prioritas tertentu sehingga setiap paket akan dilayani sesuai dengan prioritasnya. Makin tinggi prioritasnya semakin baik layanannya. Pemodelan trafik yang digunakan adalah Constant Bit Rate (CBR), routing protocol yang digunakan AODV, dan dengan pemodelan antrian router menggunakan priority queing (PQ). Parameter QoS yang digunakan average end to end delay, average end to end throughput, average packet delay variation, dan average packet loss rate. Hasilnya adalah MANET dengan implementasi QoS mampu melayani paket data dengan lebih baik. [8].

Memodifikasi protocol Babel untuk diterapkan dalam overlay network dalam jaringan di perusahaan Nexedi sebagai bagian pengembangan daro SlapOS. Jonglez dkk menerapkan penggunaan delay sebagai metric dan menerpakan metode hysteresis untuk meningkatkan stabilitas pemilihan rute. Pengujian terhadap penelitian Jonglez dkk telah dilakukan dengan studi eksperimental menggunakan jaringan overlay di dunia nyata dan simulasi dengan worst case scenario. Jonglez dkk memberikan saran untuk penelitian selanjutnya untuk melakukan studi teoritis terhadap stabilitas dan performa dari algoritma Babel [9]

Mengevaluasi kinerja routing protocol AODV, OLSR, dan ZRP diimplementasikan pada MANET menggunakan Exata atau Cyber 1.1 Simulator. Performa jaringan diukur berdasarkan mobility. Dengan parameter Quality of Service yang diukur adalah Channel Throughput, PDR (Packet Delivery Ratio), Delay, dan Jitter. Ketika mobilitas tinggi route breaks meningkat, karena route breaks dibutuhkan lebih banyak delay untuk mengirimkan paket. Hal ini menyebabkan nilai jitter tinggi. Secara umum nilai throughput rendah, nilai delay dan jitter yang tinggi hal ini tidak dapat diterima untuk real time applications. Hasil penelitian ini menunjukkan bahwa AODV, OLSR, dan ZRP tidak cocok untuk aplikasi real time[10].

\section{METODE PENELITIAN}

\section{A. Analisis Masalah}

Pada penelitian ini akan dibangun sebuah jaringan model Mobile Ad-Hoc Network (MANET) menggunakan routing protocol Babel. Perancangan ini akan diimplementasikan secara langsung di lapangan dan menggunakna Single Board Computer sebagai node pada MANET.

\section{B. Analisis Kebutuhan Sistem}


Analisis kebutuhan sistem bertujuan untuk membahas bagaimana sistem harus menyelesaikan masalah pada sistem yang akan dibangun serta mengidentifikasi kebutuhan yang terlibat untuk membangun sebuah Mobile Ad-Hoc Network (MANET). Analisis kebutuhan tersebut meliputi kebutuhan perangkat keras dan kebutuhan perangkat lunak.

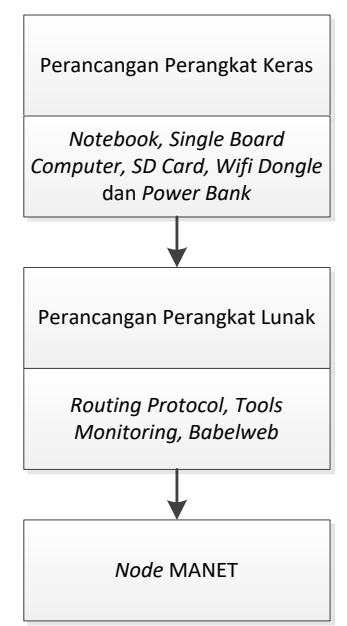

Gambar 1. Alur Perancangan Sistem Secara Umum

Gambar 1 dijelaskan mengenai perancangan sistem secara keseluruhan, dimulai dari merancang perangkat keras sistem, yang terdiri dari Notebook, Single Board Computer, Micro SDHC Card, Wifi Dongle dan Power Bank. Setelah merancang perangkat keras selesai, kemudian merancang perangkat lunak yang terdiri dari sistem operasi Ubuntu, Raspbian, perancangan routing protocol yang menggunakan routing protocol Babel, Babelweb yang nanti akan digunakan sebagai visualisasi topologi MANET.

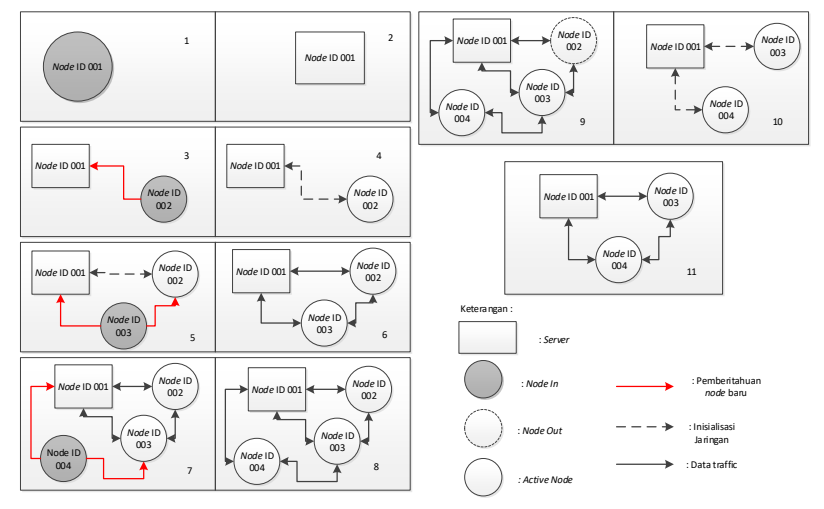

Gambar 2. Diagram Blok Ilustrasi terbentuknya MANET

Pada Gambar 2. terlihat bagaimana node membentuk sebuah jaringan Node ID 001 saat pertama diaktifkan mencara apakah ada perangkat yang sudah terbentuk. Ketika Node ID 004 masuk maka akan membentuk jaringan baru. Node ID 002 keluar dari jaringan, Server mengulang lagi proses konfigurasi dari awal dengan jumlah Node yang baru.

\section{Skenario Pengujian}

Pada Gambar 3. Pengujian pada MANET dengan kondisi multihop dengan jumlah 4 node. 


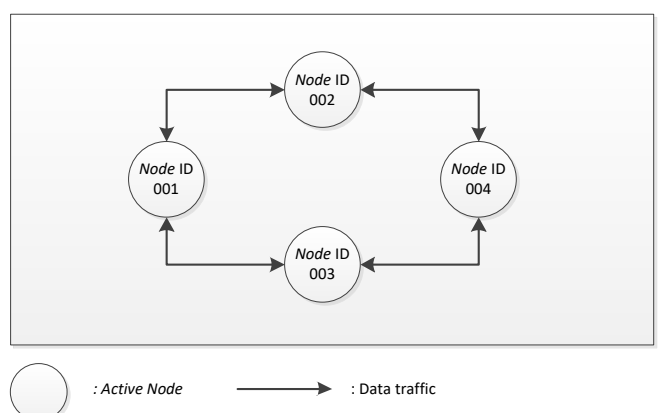

Gambar 3. Diagram blok pengujian dengan 4 node

\section{Perangkat Keras}

Implementasi perangkat keras terdiri dari implementasi sistem minimum Notebook dan SBC (instalasi sistem operasi dan aplikasi pendukung lainnya). Kemudian pemasangan Micro SDHC V-Gen 16 GB, Wifi dongle Ralink RT5370 dan Power Bank HAME T6 10.00 mAh. Implementasi dari keseluruhan perangkat keras ditunjukan pada Gambar 6.

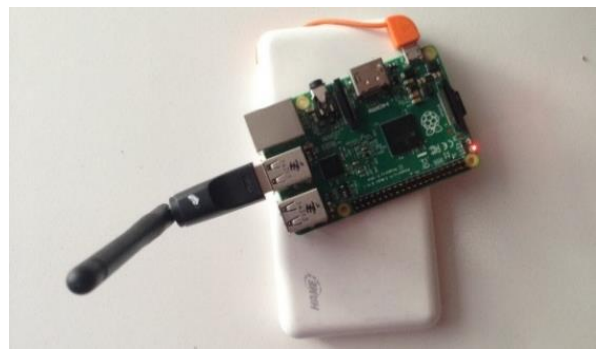

Gambar 4. Implementasi keseluruhan perangkat keras.

\section{Implementasi Sistem}

Pada implementasi sistem, penulis akan melakukan instalasi seluruh perangkat lunak yang dibutuhkan pada setiap node.

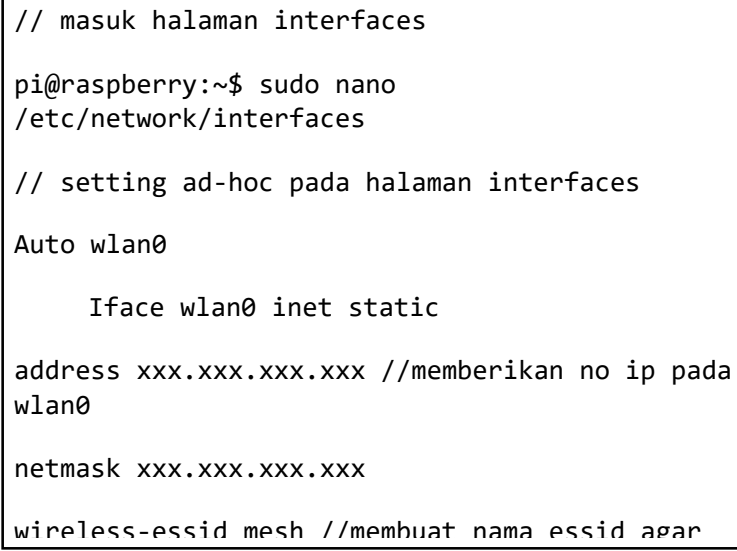


Konfigurasi MANET pada setiap node melalui terminal telah ditunjukkan pada Gambar 6 supaya konfigurasi jaringan ad-hoc bersifat tetap, penulis melakukan konfigurasi melalui halaman interfaces, yang ada di /etc/network/interfaces. Interface wlan0 di setting static karena lebih mudah dalam melakukan kontrol dari setiap node, dimana salah satunya adalah jika ada node bermasalah misalnya belum terkoneksi akan mudah untuk melakukan troubleshoot.

$$
\begin{aligned}
& \text { // instalasi protokol Babel } \\
& \text { pi@raspberry: \$ sudo apt-get install babeld }
\end{aligned}
$$

Gambar 6. Install Routing Protocol Babel

Routing protocol yang akan digunakan adalah routing protocol Babel. Gambar 7 Source code untuk menginstall routing protocol Babel.

\section{HASIL DAN PEMBAHASAN}

Pengujian pada MANET dengan routing protocol Babel ini dengan menempatkan 4 node secara multihop, 2 node terhubung secara langsung dengan node id 001yaitu node id 002 dan node id 003. 1 node lagi tidak terhubung langsung dengan node id 001, yaitu node id 004. Ketika node id 004 akan berkomunikasi dengan node id 001 harus memilih lewat node id 002 atau node id 003.

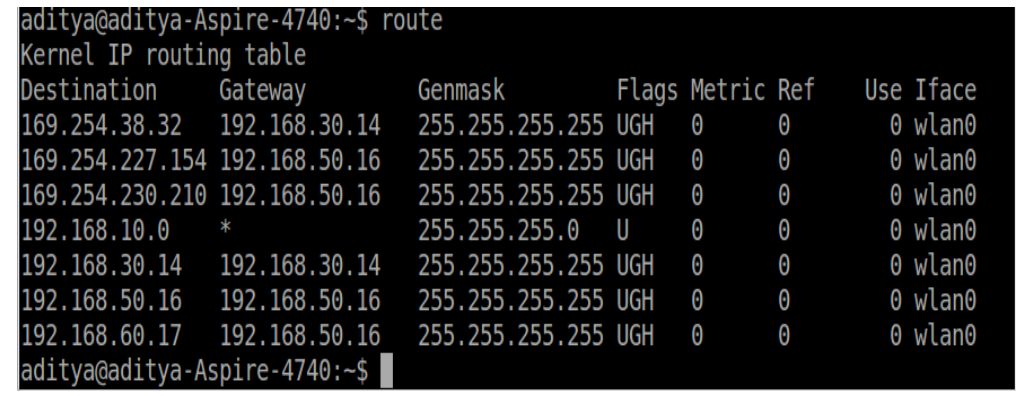

Gambar 7. Routing table sebelum terjadi kerusakan node

Pada Gambar 8 memperlihatkan belum terjadinya kerusakan route yang terbentuk untuk komunikasi dari node IP 192.168.10.12 menuju node IP 192.168.60.17 melalui node ip 192.168.50.16. Dari node ip 192.168.50.16 berkomunikasi secara langsung tanpa melalui node perantara.

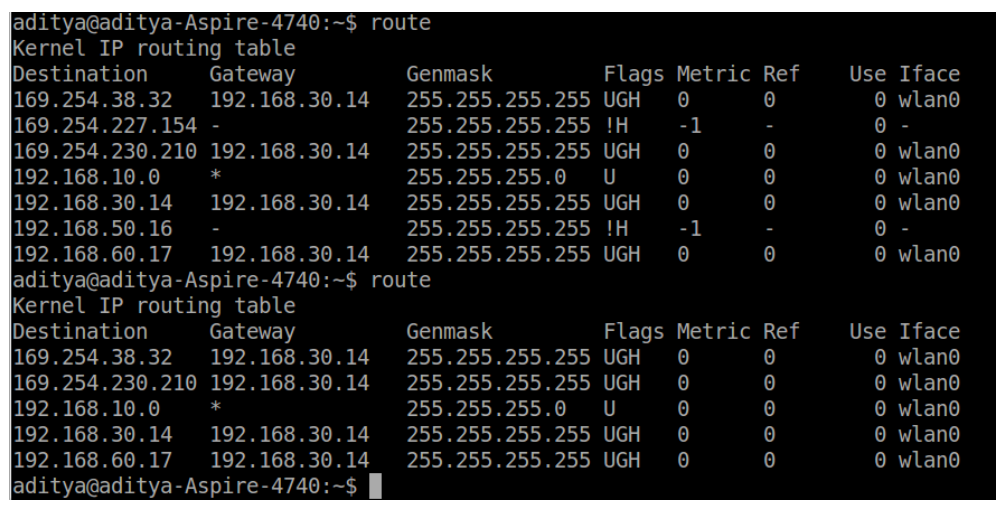

Gambar 8. Routing table setelah terjadi kerusakan 
Pada Gambar 9. memperlihatkan node IP 192.168.50.16 dimatikan untuk mensimulasikan terjadinya kerusakan pada node IP 192.168.50.16. Pada Gambar 11 memperlihatkan rute baru telah terbentuk untuk komunikasi antara node IP 192.168.10.12 dan node IP 192.168.60.17 yaitu melalui jalur node IP 192.168.30.14.

Dari segi routing protocol Babel dapat berjalan dengan baik, hal ini dibuktikan ketika ada node yang rusak babel dengan cepat membentuk route baru. Sesuai dengan karakteristik MANET yang memiliki topologi yang dinamis dan multihop

\section{KESIMPULAN}

Berdasarkan hasil pengujian yang dilakukan, konektivitas antar node dalam MANET mampu bekerja dengan baik dalam topologi yang berubah - ubah. Telah berhasil membuktikan routing protocol Babel berjalan dengan baik pada MANET, dengan terbentuknya route baru setelah terjadi kerusakan route akibat matinya salah satu node.

Untuk penelitian lebih lanjut, diharapkan terdapat LCD mini yang terpasang pada Single Board Computer sehingga untuk menerapkan teknologi MANET menggunakan Single Board Computer bisa semakin mobile. Pada penelitian lebih lanjut diharapkan menggunakan lebih banyak node, sehingga dapat diperlakukan pengujian dengan range atau jarak yang lebih luas. Pada penelitian lebih lanjut diperlukan analisis unjuk kerja dari routing protocol Babel.

\section{REFERENCES}

[1] Jonathan, R.A., 2011, Analisa Quality Of Service Pada Mobile Ad-hoc Network Dengan Optimized Link-state Routing Protocol Sebagai Jalur Nirkabel Dan Hierarchical Fair Service Curve Sebagai Metode Penjadwalan Paket. Y Yogyakarta: Universitas Kristen Dutawacana.

[2] Tavli, B., Heinzellman, W,m 2006. Mobile Ad-Hoc Network Energy-Efficient Real-Time Data Communications, Springer: USA

[3] Frikha, M, 2010. Ad Hoc Networks:Routing, QoS and Optimization, WILEY

[4] Chroboczek, J., 2011, The Babel Routing Protocol, Request for Comments: $\quad 6126$, University of Paris, France.USA: Abbrev. of Publisher, ch. x.sec. x, (year): pp-pp.

[5] Abolhasan, M., Hagelstein, B., dan Wang, J. C. P., 2009, Real-world Performance of Current Proactive Multi-hop Mesh Protocols, in Proceedings of the 15th Asia-Pacific Conference on Communications, APCC'09, IEEE Press, Piscataway, NJ, USA,pp. 42-45

[6] Fitsof, V., Vareldzihan, K., 2013, Babel Routing Protocol Research Using Quangga Software Router, State University of Telecomunication: Rusia

[7] Lego, K., Sutradar, D., 2011, Comparative study of adhoc routing protocol aodv, dsr, and dsdv in mobile ad hoc network 1.

[8] Saortua, C., 2010, Analisis dan Simulasi Differentiated Service QoS Pada Mobile Ad-hoc Network". Bandung: Telkom University.Jonglez, B., Boutier, M., dan Chroboczek, J., 2014. A Delay-based routing metric, Computing Research Repository (CoRR) abs/1403.3488

[9] Jonglez, B., Boutier, M., dan Chroboczek, J., 2014. A Delay-based routing metric, Computing Research Repository (CoRR) abs/1403.3488

[10] Sharma, S. K., Sharma, S., 2016, Performance Evaluation of Routing in MANETs based on QoS parameters, international Journal of Modern Computer Science and Applications (IJMCSA) ISSN: 2321-2632 (Online) Volume No.-4, Issue No.-1. 